\title{
Spelling Errors of Omani EFL Students
}

\author{
Sheikha A. Al-Bereiki* \\ \& \\ Abdo M. Al-Mekhlafi \\ Ministry of Education, Sultanate of Oman Sultan Qaboos University, Sultanate of Oman
}

Abstract: The purpose of this study was to explore the types of spelling errors students of grade ten make and to find out whether there were any significant differences between males and females with respect to the types of spelling errors made. The sample of the study included 90 grade ten students from four different schools in North Batinah. The researchers manipulated the use of a test that consisted of two questions: an oral dictation test of 70 words with a contextualizing sentence and a free writing task. The misspellings were classified into nine different types. The findings revealed that the most common spelling errors among Omani grade ten students were vowel substitution, then came vowel omission in the second place and consonant substitution in the third place. Male students omitted more vowels than female students while females made more true word errors than their male counterparts. In light of the findings, the study presents some recommendations and suggestions for further studies.

Keywords: Spelling errors, errors, ESL/EFL, error analysis.

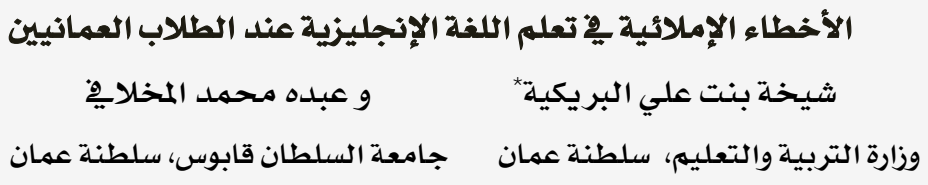


The process of learning a second or foreign language is challenging. Thus, ESL/EFL learners face difficulties with various aspects of the language including spelling. Spelling is considered as the starting point of the written language as indicated by Mahmoud (2013). Also, writing compositions demands a high level of spelling proficiency in order to produce a good piece of writing. Allred (1990) pointed out that spelling ability can influence the writer's effectiveness and creativity.

The ability of encoding a sound or phoneme into the appropriate corresponding grapheme or spelling is complex to many learners of English. Likewise, Arab learners of English face various difficulties when learning English spelling. A large body of research analyzes students' errors as a way of gaining insight into how students learn and how to address their learning needs. For example, Brown (2000) encouraged systematic analysis of learners' errors in order to address their needs via designing appropriate curricula. A considerable amount of research has been devoted to analyze the patterns of spelling errors (AlHarrasi, 2012). These studies surveyed the errors in spelling and then classified them into distinct categories. Studies done in the Omani context have surveyed spelling difficulties at either early grade levels like grade five and six or at a tertiary level. To the researchers' best knowledge, no study about learners' spelling difficulties has been conducted on high school students. Therefore, this study aims to find out the most common spelling errors grade ten EFL students in Oman make.

\section{Purpose of the study}

The purpose of this study is to analyze the spelling errors of grade ten EFL students in Oman. It also aims to find out whether there are any significant differences between male and female students with respect to the types of the spelling errors made.

\section{Study questions}

1. What are the most common types of spelling errors made by Omani grade ten EFL students?

2. Is there a statistically significant difference between male and female students regarding the types of the spelling errors made?

\section{Literature review}

\section{Spelling and its related concepts}

Spelling is often defined as the process of recognizing and reproducing sounds of language into a sequence of letters in a written form or in an oral form (Santoro, Coyne \& Simmons, 2006). It is also defined as "the grammar of letter sequences that generates permissible combinations without regard to sound" (Peters, 1985, p. 11-12). Here, the definition suggests that spelling is not a task of translating sounds into their corresponding letters in a direct sound to letter relationship. It is more complex than this. There are rules that govern letter combinations. Spelling is a challenging skill to master because it is made up of different layers of knowledge.

Spelling, as Moats (1984) indicated, is a multifaceted skill that depends upon several layers of knowledge; phonological awareness, morphological awareness, semantic knowledge and orthographic knowledge (cited in Santoro, Coyne \& Simmons, 2006). Phonological awareness is the ability to identify sounds in spoken words as explained by Bourassa and Treiman (2009). It is the explicit knowledge of the sounds' system in the language (Santoro, Coyne \& Simmons, 2006). Morphological awareness is defined by Bourassa and Treiman (2009) as the knowledge of relations among word forms and how they influence spelling. Semantic knowledge is "the knowledge of the effect of spelling on word meanings and vice versa" (Apel, 2008, p.15). Wasowicz (2007) explained morphological knowledge and semantics relationships as the knowledge that allows the individual to spell inflected words (that contain suffixes and provide information about time or quantity without changing the meaning, e.g. walk-walked, cat-cats) and derived forms (that contain suffixes or prefixes and can change the meaning and sometimes the class of words, e.g. friend-friendly). Bourassa and Treiman (2009) explained orthographic knowledge as the knowledge of legal and illegal letter sequences. It can also refer to, as indicated by Apel (2008), the use of spelling rules and patterns. It is also, according to Apel (2008), the knowledge that governs the alphabetical principles, for example, a $/ \mathrm{k} /$ sound can be k, c, cc, ch, ck, qu or $\mathrm{x}$, and a (gh) can be pronounced as a /f/ or a /g/. It also covers knowledge of rules for combining letters, for 
instance, there is no letter string like $(\mathrm{kr})$ in English. In spelling, the concern is in letter sequences not word sequences.

\section{Significance of correct spelling}

The emphasis of spelling accuracy is closely related to its role in successful writing, effective communication, its link to courtesy and self-concept, its role in success at school and other educational pursuits, and finally its relation to success in society.

Treiman and Kessler (2013) pointed out that learning to spell is important "because human attention is limited. Children who must devote a good deal of attention to spelling have fewer mental resources available for other aspects of writing" (p. 317). Thus, being a good speller reserves mental effort for other aspects of writing. McMurray (2006) explained that a speller with automatic spelling skills can produce a high standard piece of writing since $\mathrm{s} / \mathrm{he}$ has more resources in working memory for other composition skills. Indicated by Kreiner, Schnakenberg, Green, Costello and McClin (2002), poor spelling denotes lower writing ability since spelling is a component of successful writing. Also, writing is seen as a permanent activity. What we write remains there for anybody to read, criticize, or notice any errors. One's writing reflects his/her education, reliability and even intelligence (Jennings, 1998; Stirling, 2011).

There are also reasons that concern communication. Spelling words correctly is crucial because spelling conveys meaning, grammar and intent; thus misspellings may interfere with comprehension and eventually may hinder communication between the writer and the reader (Apel, 2008; Jennings, 1998; Peters, 1985). A similar notion expressed by the Department of Education and Children's Services in Australia (DECS) (2011) illustrated that the purpose of spelling is for the writer to communicate the ideas clearly and properly and for the reader to understand the written message. Thus, poor spelling affects written communication negatively. Additionally, several researchers (Kohnen, Nickels \& Castles, 2009; Peters, 1985; Stirling, 2011; Warda, 2005) pointed out that poor spelling capabilities affect the individual's choice of words in writing, forcing learners to avoid using certain words because they are not certain of their spelling. Consequently, written production may fail to convey its intended message.

Additionally, there is the question of courtesy which is connected to spelling as it is connected to speaking and writing. Educated people have to acquire the habit of being precise (Peters, 1985). Being precise requires being able to write what exactly conveys the meaning, not avoiding certain words for being difficult. What is more is that good spelling contributes effectively to a learner's self-concept. It gives any person the status and knowledge to communicate adequately and acceptably in writing (Peters, 1985).

Accurate spelling is of high importance and teachers have the responsibility for convincing learners that accurate spelling is mandatory for several parts in their exams. It is also required for job applications and businesses. Conversely, poor spelling reflects negatively on the individuals and companies that employ it (Warda, 2005).

The last point has to do with international proficiency tests (e.g. TOEFL and IELTS). Test takers are penalized for spelling errors in these major scale tests. Students and job seekers are required to display a certain level of English proficiency reflected in TOEFL or IELTS. Thus, spell checkers are not available in circumstances where students and test takers have to demonstrate their knowledge of English (Cook, 1999).

\section{The definition of error}

Any learning experience is most likely to involve attempts of learners as trial and error which might end up with making errors. It is essential to make a distinction between mistakes and errors. According to Corder (1981, cited in Al-Jayousi, 2011), mistakes are incorrect instances that are a result of performance. They are said to be slips that learners can correct by themselves. However, errors are the incorrect outputs that are due to problems in the underlying knowledge of the learner. Here, the learner lacks the competence to rectify the inaccurate responses.

\section{Error analysis and its significance}

Error analysis has gained a considerable amount of attention by scholars. It is defined as "the process of determining the incidence, nature, causes and consequences of unsuccessful language" (James, 1998, p.1). 
Learners' errors are significant for various instructional reasons. For example, studying learners' errors can throw some light on how learners process language and what kind of assistance they need. Wasowicz (2007) emphasized the notion that spelling errors can inform educators about the kind of linguistic knowledge individual learners possess. Also, studying learners' misspellings can inform educators about which stage of spelling development the learner is stuck at. This assessment, as indicated by Kohnen, Nickels and Castles (2009), can draw the training framework and the types of strategies needed for the learner in order to move to the next stage. It is emphasized by DECS (2011) that the teacher can best assist learners by analyzing their writing, looking for recurring patterns and discussing with them ways of successful learning. Kohnen, Nickels and Castles (2009) suggested identifying learners' spelling difficulties as early as possible in order to enhance spelling abilities and to facilitate text writing.

Identifying the types of spelling problems is of central importance in the process of spelling error analysis. Some research work has been devoted to analyze the patterns of spelling errors (Al-Harrasi, 2012) and findings of spelling errors' studies vary according to the aims of each study (Emery, 2005). Consequently, different studies used different systems for classifying the spelling errors. For example, Al-Jarf (2010) suggested classifying spelling problems into phonological and orthographic problems. Cook (1997) classified spelling errors into four types: the first type was omission and addition, the second was substitution, the third was transposition and the fourth was called sound-based errors. Other researchers such as Al-Harrasi (2012), Al-Jabri (2006), Al-Zuoud and Kabilan (2013) and Khan and Itoo (2012) followed the classification of spelling errors suggested by Cook (1997). Mahmoud (2013) classified spelling errors in his corpus into inter-lingual and intra-lingual. He justified his two-way classification for the purpose of finding implications for classroom instruction. Classifying spelling errors into different categories helps detect the sources of difficulties and would consequently facilitate the choice of the appropriate classroom instruction.

Al-Jayousi (2011) classified spelling errors according to their types and to their likely caus- es. He classified misspellings according to their types into six categories; substitution, omission, addition, disordering, segmentation and unrecognizable. Misspellings were classified into three categories according to their likely causes:

1. irregularity of English (errors mostly caused by the non-phonetic nature of the English orthographic system),

2. mother tongue interference (which included errors that involve misuse of sounds like $/ \mathrm{p} /, / \mathrm{v} /$ and $/ \mathrm{t} / /$, consonant clusters, confusion in using mirror letters: $\mathrm{b} / \mathrm{d}, \mathrm{p} / \mathrm{q}$ and deletion of short vowels: writing son for seven, and

3. lack of knowledge of spelling rules and their exceptions.

Very few studies focused on other aspects of spelling errors such as gender differences. Allred (1990) investigated gender differences in spelling achievement of male and female students from grade one through grade six in the United States. He compared the spelling achievement of boys and girls on both a spelling test and a proofreading standardized test. The researchers found out that girls were better spellers than boys in all grade levels. Allred discussed possible reasons for the gender differences in spelling achievement; two of which were maturation and cultural expectations. Maturation favors girls over boys since girls mature earlier than boys.

Cook (1999) carried out a study with the purpose of looking at students' spelling errors with specific L1s. Cook's study looked at 1,498 errors made by eleven different groups of preuniversity students including Arab learners. The analysis revealed that ESL Arab learners substituted vowels (e.g. obundant for abundant), added 'epenthetic' vowels (e.g. punishement for punishment) and made phonological errors (e.g. manshed for mentioned). The researcher collected the errors from their writings. However, students' writings do not always reveal all types of errors students may make since topic familiarity is under question (Cramer, 1998). Students may avoid writing words if they are not certain of their spelling (Schonell, 1985). Arabs speak different dialects which are themselves quite distinct from Standard Arabic Language (Fender, 2008), yet 
Cook did not indicate which background those Arab students came from.

A number of studies have analyzed learners' spelling errors conducted in the Omani context. A study done by Al-Harrasi (2012) on grade six female students utilized the spelling list suggested by Cook (1997). However, the words in Cook's spelling list are not normally covered in grade six syllabus. Kibel and Miles (1994) stated that words selected for spelling tests should be ones that students are familiar with. Al-Jabri (2006) conducted a study on grade five students who were taught Our World Through English (OWTE) syllabus in their second year of learning a foreign language and it revealed similar results to AlHarrasi's study. A third study was conducted with tertiary students in Dhofar University by Vaddapalli (2012). The researcher tested students' difficulties in spelling three-letter words containing one vowel for the purpose of highlighting spelling and auditory discrimination difficulties of students in Oman. He found that students misused most of the vowels and some of the consonants. For example, $95 \%$ of the students misspelled the word 'rub' and instead they wrote rup, rap, rab, raue, rib.

A study done by Al-Mezeini (2009) on grade nine learners of general education in Oman revealed that explicit teaching of spelling rules did not improve students' performance in spelling tests but it helped to improve their writing performance. The researcher manipulated the use of an oral dictation test and a free writing task in order to collect his data. In his study, sound-based spelling errors constituted the largest category for a percentage of 55 . Cook (1999) found out that sound-based spelling errors came in third place with $6 \%$. This supports the fact that ESL learners who have different L1s face different spelling difficulties due to the interference of their mother tongue. An obvious limitation to Al-Mezeini's study would be the kind of intervention he employed in his teaching of spelling rules.

A preliminary field survey conducted by the researchers of the present study on the analysis of the academic year's $(2012 / 2013)$ summative English language examination results of grade ten Basic Education has revealed some important findings. This survey study included four cycle two (5-10) schools. Students in grade ten scored very low marks in vocabulary questions that required accurate spelling.
In some cases, the percentage of passing in the vocabulary question was as low as $8 \%$. A look at the analysis of writing questions showed that students scored low marks too. In some schools, the percentage of failure was higher than the percentage of passing. All in all, the anecdotal evidence of the analysis of 2012/2013 summative English language examination results uncovered the fact that students of grade ten face difficulties in spelling (Afra School 5-10; Hunain School 5-10; Jumanah School 5-10; Khadeejah School 5-10, personal communication, November 14th, 2013). But, what are the types of their spelling errors?

Studies done in the Omani context have surveyed spelling difficulties at either early grade levels such as grade four (Al-Yahyai, 2009), grade five (Al-Hassan, 2006; Al-Jabri, 2006) and grade six (Al-Harrasi,2012 ) or at a different educational system such as grade nine of general education (Al-Mezeini, 2009) or at a tertiary level (Emery, 2005; Mahmoud, 2013 Vaddapalli, 2012). To the researchers' best knowledge, no study about learners' spelling difficulties has been conducted on high school students in Oman. Expressed by Emery (2008), good spelling is necessary for secondary students simply because their "courses are geared towards passing written exams" (p.17). Therefore, studying grade ten students' spelling errors is critical for a number of reasons. Firstly, students are at a different age level from students being studied in previous research studies, and they have been learning English for almost ten years. Secondly, anecdotal evidence shows that tenth graders suffer from difficulties in their spellings. Thirdly, the tenth graders are assessed differently from all previous grade levels ( 25 marks out of the total 100 are allocated for writing and 5 marks are given for accurate spelling in a vocabulary question). In addition, grade ten marks the end of cycle two of basic education. So, students are expected to compose more complex texts displaying proficiency in different language skills including spelling (Ministry of Education, 1999). Thus, studying learners' spelling difficulties can help improve their writings (Al-Jabri, 2006) and their language proficiency. In light of the above discussion, there is a need to investigate spelling errors made by grade ten students. 


\section{Methodology}

\section{Population and sample}

The study population comprised all students in grade ten Basic Education in North Batinah Governorate. There were 280 male classes, 259 female classes and 5 coeducation classes in North Batinah Governorate. So, two male classes and two female classes were the random sample in this study. Table 1 displays the distribution of male and female students who took the test and their test papers were valid for analysis.

Table 1

Distribution of male and female students who participated in the study

\begin{tabular}{lc}
\hline Gender & No. of students \\
\hline Male students & 41 \\
Female students & 49 \\
Total & $\mathbf{9 0}$ \\
\hline
\end{tabular}

\section{Instruments}

An English test was given to grade ten students. It was designed in order to find out the most common types of spelling errors students of grade ten in North Batinah Governorate in Oman make. It was also intended to find out whether there were any significant differences between Omani male and female EFL students with respect to the types of spelling errors made.

The English test had two questions: a dictation question and a free writing task. There were seventy words in the dictation test. There were also contextualizing sentences, a sentence for each spelling word. The words were selected on the basis of familiarity and frequency. According to a curriculum specialist in the Ministry of Education, vocabulary selection in grade ten of basic education and other grade levels is topic-related. Word lists at the back of the skills books (grades 8-10) and at the back of the class books (grades 5-7) include new vocabulary related to the topics of each unit and words that are commonly used (Al-Jardani, personal communication, January. $\left.8^{\text {th }} .2014\right)$. Schlagal (2002) argued that content vocabulary lists are problematic in different ways. They are challenging, they contain lower frequency words and they do not reflect any orthographic patterning since they have been selected for the purpose of advancing ideas and not to teach orthography. Therefore, students will be learning the spellings of words which they probably won't use in their writings. Thus topic-related vocabulary at the back of grade ten text books was not included in the dictation question.

Using words from frequency lists to assess students' progress in spelling has several advantages. Schlagal (2002) pointed out that words in these lists are sequenced according to their frequency of use. The words students learn are the ones that they will need in their writings. Secondly, the word frequency lists are ordered by level of difficulty. Easier words come first. A very interesting idea highlighted by Schlagal is that "the 4000 most frequently used words constitute nearly $98 \%$ of the vocabulary used by children and adults in and out of school" (2002, p.46). Thus, the underlying principle of the vocabulary selection for the oral spelling test should be frequency of use as well as familiarity with the words.

Therefore, in order to ensure familiarity of the selected vocabulary, the words were selected from previous grades (grade 5 to grade 9). Then, these words were checked against the Word Zone for 4,000 simple word families ("Text Project," 2012) to ensure their frequency. Informal interviews with grade ten teachers were made to further ensure the familiarity and frequency of the selected words. The chosen words represented various aspects of the spelling system; regularly spelled words; e.g. got and hand, irregularly spelled words; e.g. daughter, homophones; e.g. their and wear, and morphologically derived words; e.g. education and entertainment. (See appendix A for the spelling words).

The second question was a free writing task. The students were asked to write about a given situation. Again, the researchers discussed the possible topics with some grade ten teachers and topic familiarity was taken into consideration.

The primary version of the English test was validated by a panel of experts. The validation panel included two faculty members in the College of Arts at SQU, one faculty member in the College of Education at SQU, one curriculum officer in the Ministry of Education, two English language supervisors from North Batinah Governorate, one senior English teacher and an English teacher from North Batinah Governorate. 
It included seventy words for the oral spelling question and three topics in the writing question for students to choose one and write about. The validators had to give their comments on the level of difficulty of the selected spelling words, the number of words, the clarity of the contextualizing sentences and the level of difficulty for the topics selected to choose from in writing. Feedback from the validity check panel included changing some of the contextualizing sentences for the sake of more clarity and limiting students to one topic in the writing question in order to save students' time and to keep them focused. Thus, the final English test was modified accordingly.

In order to ensure the reliability level of the English test, the validated version of the test was piloted on two grade ten classes: 25 male students and 27 female students. These two classes were not included in the actual implementation of the test later on. The first question of the test was marked in terms of accuracy of spelling. Then, the internal consistency of the test was measured using Cronbach's alpha test in the Statistical Package for the Social Sciences (SPSS). The result showed that the oral spelling test had a high level of consistency as Cronbach's alpha coefficient was $\mathrm{r}=$ 0.97. In order to ascertain the reliability of the scoring of the writing question, inter-rater reliability was calculated using Pearson's correlation coefficient between the ratings given by the researchers and those given by a senior English teacher. The correlation coefficient of the writing question was $\mathrm{r}=0.93$, which was a high level of inter-rater consistency. The following procedure was followed in administering and marking the test.

1. Students were firstly oriented with the test, its purpose and its questions. Then, an example was given in order to clarify the instructions for the first question. Then, the test administrator, the researchers of the present study, read the word once. Then, the word was repeated in the context of a sentence. Finally, the word was read twice. This procedure has been followed by Al-Yahyai (2009) among other researchers. Once the first question was completed, the test administrator discussed the writing topic with the students in order to generate ideas to write about.
2. For question one, the oral test, each instance was marked as either correctly, incorrectly spelled or no attempt. If the spelling of the word was incorrect, then the type of the error was identified. The spelling errors were classified under nine distinct categories. These categories were consonant omission, vowel omission, consonant insertion, vowel insertion, consonant substitution, vowel substitution, transposition, complex word errors and true word errors. It is noteworthy that substitution, omission, insertion and transposition were the most common classifications used in literature (AlJayousi, 2011). Also, the first seven categories were straightforward adaptations from Brooks, Gorman and Kendall (1993) for L1 children and Bebout (1985) for L2 adults (cited in Cook, 1999). The last two categories were adapted from Emery (2005). Below is a detailed description of the categories used to classify the spelling errors.

A. Consonant omission refers to the deletion of one consonant letter or more from the target word.

B. Vowel omission refers to the deletion of one vowel or more from the target word.

C. Consonant insertion refers to the addition of one consonant letter or more in the target word.

D. Vowel insertion refers to the addition of one vowel letter or more in the target word.

E. Consonant substitution refers to the replacement of a consonant letter or more for others. This also involves substituting a consonant digraph or tri-graph.

F. Vowel substitution refers to the replacement of a vowel letter or more for others. This also involves substituting a vowel diagraph or a tri-graph.

G. Transposition refers to reversing the order of a letter or some letters in a word. Transposition is treated as one category with disregard to the type of letter being mis-ordered. This includes mis-ordering of: 
1. one letter as in reversing the order of two correctly adjacent letters such as writing caemra for camera,

2. one letter as in reversing the order of two adjacent letters, one of them is not a correct letter in the word as in writing akmre for camera,

3. one letter as in reversing the order of two letters which are not adjacent to each other as in writing deegre for degree and bussines for business; this counts as one transposition,

4. two letters in the place of each other as in misplacing the $e$ and the $i$ as writing cimestry for chemistry; this counts as two transpositions, and

5. two letters in the place of two other letters as in bussnies for business; this counts as two transpositions.

H. True word spelling error: Here, the target word is spelled as another word, e.g. writing live instead of leave.

I. Complex spelling error refers to the misspellings that have more than two types of spelling errors or the spelling is not readable or has no explanation, e.g. apaksi for education, or durt for their.

J. The different types of misspellings were counted manually for every student and recorded in a table.

K. For question two, the written text for each student was read twice. Misspellings were underlined and then classified. After that, different types of spelling errors were counted manually for every student and recorded in a table. The writing question differed from the oral spelling question in terms of the absence of two categories; correct spelling and no attempt, and that was due to the nature of the two questions.

L. A second rater classified the spelling errors of a random sample from the test papers. This step was important because it ensured consistency of classification. The second rater was a senior English teacher. It was decided that one English test paper would be done by the second rater for the first test question since there were seventy words. Four test papers would be done for the free writing question since students wrote passages with different lengths. The level of agreement between the researchers and the second rater was .88 for the oral spelling question and .90 for the free writing question. Both correlation coefficients showed a high level of agreement indicating a high level of consistency in the classification of errors.

M. A second review by the researchers was carried out to further ensure the consistency and accuracy of classification of errors. A few changes were made accordingly.

N. A third table was created to include the errors of both questions.

O. The data in the three table were entered in the SPSS to run the appropriate statistical procedures in order to answer research questions one and two.

\section{Findings and Discussions}

The first question: What are the most common types of spelling errors made by Omani grade ten EFL students?

Table 2 shows the sums and percentages of the different types of spelling errors for grade ten students in both test questions one and two. It is noteworthy that correct spellings and no attempts to spell the words were also recorded, yet they were not included in the tables of the types of spelling errors because they were not errors.

Table 2

Sums and percentages of different types of spelling errors for all students in test questions one and two

\begin{tabular}{lcc}
\hline Types of spelling errors & Sum & *Percentage \\
\hline Vowel substitution & 2,470 & $24.58 \%$ \\
Vowel omission & 2,131 & $21.29 \%$ \\
Consonant substitution & 1,698 & $16.90 \%$ \\
Complex spelling error & 1,246 & $12.40 \%$ \\
Consonant omission & 1,039 & $10.34 \%$ \\
True word error & 535 & $5.32 \%$ \\
Vowel insertion & 524 & $5.21 \%$ \\
Transposition & 271 & $2.70 \%$ \\
Consonant Insertion & 136 & $1.35 \%$ \\
$\quad$ Total & 10,050 & \\
\hline
\end{tabular}


*out of the total number of errors

Students made a large number of spelling errors. Over ten thousand spelling errors were made by ninety students and that shows how big the spelling problem is among this grade. Table 2 presents the types of spelling error committed by the students. Vowel substitution was the most common type of spelling error made by students. Vowel omission was the second most common spelling error. The third in the list of spelling problems was consonant substitution while complex spelling errors came in fourth place. Finally, consonant insertion was the least common typeof spelling error. For specific details of the types of spelling errors made by students, table 3 and table 4 displays the sums and percentages of the different types of spelling errors for all students in questions one and two of the test respectively.

Table 3

Sums and percentages of the different types of spelling errors for all students in question one of the test

\begin{tabular}{lrl}
\hline $\begin{array}{l}\text { Types of the spelling } \\
\text { errors }\end{array}$ & Sum & Percentage \\
\hline Vowel Substitution & 2,243 & $24.54 \%$ \\
Vowel Omission & 1,959 & $21.43 \%$ \\
Consonant Substitution & 1,595 & $17.45 \%$ \\
Complex Spelling Error & 1,214 & $13.28 \%$ \\
Consonant Omission & 941 & $10.29 \%$ \\
Vowel Insertion & 446 & $4.88 \%$ \\
True Word Error & 440 & $4.81 \%$ \\
Transposition & 186 & $2.03 \%$ \\
Consonant Insertion & 117 & $1.28 \%$ \\
Total & 9,141 & \\
\hline
\end{tabular}

Table 3 shows that the most common spelling error in question one of the test vowel substitution. Vowel omission types of errors were in second place. Consonant substitution spelling errors and complex spelling errors represented the third and fourth types of errors respectively. The least common spelling errors were consonant insertion.

Table 4

Sums and percentages of the different types of spelling errors for all students in question two of the

\begin{tabular}{lrl}
\multicolumn{2}{c}{ test } & \\
\hline Types of spelling errors & Sum & Percentage \\
\hline Vowel Substitution & 255 & $27.36 \%$ \\
Vowel Omission & 171 & $18.35 \%$ \\
True Word Error & 99 & $10.62 \%$ \\
Consonant Substitution & 96 & $10.30 \%$ \\
Consonant Omission & 86 & $9.23 \%$ \\
Vowel Insertion & 78 & $8.37 \%$ \\
Complex Spelling Error & 66 & $7.08 \%$ \\
Transposition & 62 & $6.65 \%$ \\
Consonant Insertion & 19 & $2.04 \%$ \\
Total & 932 & \\
\hline
\end{tabular}

Table 4 displays the sums and percentages of the different types of spelling errors made by grade ten students in the second question of the English test, the free writing task. There is a very similar order of the different types of spelling errors as being mostly made by the students to the order in question one and when the misspellings were combined in the two test questions. In table 4, vowel substitution and vowel omission came in the first and second places respectively, similar to tables 2 and 3. The least common type of spelling error was consonant insertion. However, true word spelling errors were in third place and consonant substitution came in fourth place.

Noticeably, the order of the types of spelling errors as the most common and the least common is the same for question one of the test, question two of the test and when combining both questions one and two of the test. Similarities are apparent in the order of the types of the misspellings for the first and second and the least common. Differences occurred in the orders of the other types. A simple explanation for this is that the largest number of spelling errors were made in question one since students were asked to write certain words while in question two students had to use their own knowledge in order to generate their written compositions. Students did not write much in the second part of the English test, the free writing task, and thus the number of spelling errors found in students' text writing was not high compared to the spelling errors made in the oral spelling question.

The findings in tables 2, 3 and 4 correspond with the findings of some previous studies. Discussion in this section uses table 2, where all the spelling errors from both test questions are included. Corresponding with the present study's findings, Emery (2005) found that vowel substitution was the most common type of spelling errors among all other types of errors that involved vowel letters. Also, Al-Jarf (2008) found out that substituting the vowel by another faulty vowel was the most common specific strategy used by university students in her study.

Previous studies (Al-Harrasi, 2012; Al-Zuoud \& Kabilan, 2013) showed that substituting the correct letter with another letter was the most common spelling erroramong their students involved in the studies; however, the research- 
ers did not specify the types of letters that were most problematic; were they substituting the vowels or substituting the consonants?

Additionally, Al-Hassan (2006) found that consonant substitution was of particular difficulty to Omani grade five male students in his study. The researcher indicated that his learners had difficulty with mirror-shaped letters, e.g. $b$ and $d$, but he did not include any percentages or means of all the error types in his analysis of misspellings.

Al-Jabri (2006) found that substitution and omission spelling errors were the most common among his students. Yet, the researcher did not specify the types of letters. Also, the findings of Al-Jayousi's (2011) study revealed that spelling errors of Arab learners of English in the UAE were highly concentrated in substitution errors with as high as $50 \%$ while omission came in second place with $33 \%$.

On the other hand, the findings of the present research study were not in consistency with Al-Mezeini's (2009) study which he conducted with Omani grade nine male students. The researcher found that sound-based spelling errors were the most common spelling errors $(55 \%)$ while substitution and omission were categorized in second place (35\%). Obviously, Al-Mezeini followed a different categorization from the one followed in the present study since sound-based misspellings were not specified in the present study. Substituting the correct vowel with another vowel was found to be the most common type of misspelling among grade ten students. This finding might raise the concern about phonemic awareness in the vowel sounds students possess. Vaddapalli (2012), in his study about spelling and auditory discrimination difficulties students in Oman face, concluded that "lack of phonemic awareness of English sounds is one of the main reasons of spelling problems" (p.273).

Vowel related spelling errors seemed to be more problematic for Arab EFL learners of English than consonant related misspellings. According to table 2, vowel substitution came in first place while consonant substitution came in third place. Similarly, vowel omission was the second most common type of misspellings while consonant omission was the fifth. Vowel insertion came in seventh place whereas consonant insertion was the least common type of misspellings. This suggests that vowels constitute particular difficulties for Arab learners of English. The literature supports this finding. Emery (2005) found out that vowel-related spelling errors constituted $83 \%$ among all the spelling errors in the corpus collected by the researcher compared to $17 \%$ consonant-only misspellings. Additionally, Cook (1999), in his analysis of the spelling errors made by L2 users of English from different L1s, indicated that Arab learners substituted vowels and added more vowels than other L2 users and the researcher attributed this to the linguistic differences between English and Arabic. A question to be raised: were there certain vowel that were more problematic than others? This is a question that may constitute a possible area of future research studies.

The second question: Is there a statistically significant difference between male and female students regarding the types of spelling errors made?

This question was answered by comparing the types of spelling errors of male and female students. Table 5 displays t-test results for differences between males and females in mean spelling errors in question one and question two.

The results presented in table 5 revealed that there were significant differences between male and female students with respect to two types of misspellings; vowel omission and true word errors. Male students omitted more vowels when spelling as opposed to female students. Similarly, more female students made true word errors compared to their male counterparts. 
Table 5

\begin{tabular}{|c|c|c|c|c|c|}
\hline Types of spelling errors & Gender & Mean* & SD. & $\mathrm{T}$ & Sig.(2-tailed) \\
\hline \multirow[t]{2}{*}{ Consonant Omission } & Male & 12.60 & 4.91 & 1.77 & 0.08 \\
\hline & Female & 10.88 & 4.33 & & \\
\hline \multirow[t]{2}{*}{ Vowel Omission } & Male & 27.27 & 10.65 & 3.23 & $0.00 * *$ \\
\hline & Female & 20.67 & 8.71 & & \\
\hline \multirow[t]{2}{*}{ Consonant Insertion } & Male & 2.18 & 1.39 & 0.11 & 0.92 \\
\hline & Female & 2.14 & 1.29 & & \\
\hline \multirow[t]{2}{*}{ Vowel Insertion } & Male & 5.29 & 3.53 & 1.49 & 0.14 \\
\hline & Female & 6.53 & 4.20 & & \\
\hline \multirow[t]{2}{*}{ Consonant Substitution } & Male & 20.80 & 9.70 & 1.91 & 0.06 \\
\hline & Female & 17.24 & 8.00 & & \\
\hline \multirow[t]{2}{*}{ Vowel Substitution } & Male & 27.22 & 10.57 & 0.18 & 0.86 \\
\hline & Female & 27.63 & 11.58 & & \\
\hline \multirow[t]{2}{*}{ Transposition } & Male & 3.61 & 2.64 & 0.46 & 0.65 \\
\hline & Female & 4.05 & 4.54 & & \\
\hline \multirow[t]{2}{*}{ True Word Error } & Male & 5.17 & 2.60 & 2.21 & $0.03^{* *}$ \\
\hline & Female & 6.59 & 3.36 & & \\
\hline \multirow{2}{*}{ Complex Spelling Error } & Male & 16.33 & 10.73 & 1.59 & 0.12 \\
\hline & Female & 12.89 & 9.31 & & \\
\hline
\end{tabular}

*The average of misspellings for each student

** The mean difference is significant at 0.05 level

Vowel omission is a characteristic of a speller at the phonetic stage of spelling development. There were more male students at the phonetic stage than female students. This is quite alarming since phonetic spelling is an attribute of young learners' writing. Making true word errors shows that the students have good knowledge of permissible strings of letters and the constituents that are more likely to make correct words in English language. Students who make more true word errors can be said to know how a word looks right or have good orthographic knowledge; however, their semantic knowledge is poor. More exposure to the language through directed reading or extensive reading can help students develop good semantic knowledge. For specific de- tails, tables 6 and 7 represent the t-test results for the differences between males and females in mean spelling errors for question one only and question two only respectively.

With reference to table 6 , there were significant differences between males and females with respect to types of spelling errors in three categories; vowel omission, consonant substitution and true word errors. Table 6 reveals that male students made more vowel omission misspellings than their female counterparts. Also, they used the incorrect consonant in their spellings more frequently than female students. Similar to the findings in table 5, female students made more true word errors than male students.

Table 6

T-test results for differences between males and females in mean spelling errors in question one only

\begin{tabular}{|c|c|c|c|c|c|}
\hline Types of spelling errors & Gender & Mean* & SD. & $\mathrm{T}$ & Sig.(2-tailed) \\
\hline \multirow[t]{2}{*}{ Consonant Omission } & Male & 11.34 & 4.68 & 1.33 & 0.19 \\
\hline & female & 10.13 & 3.85 & & \\
\hline \multirow[t]{2}{*}{ Vowel Omission } & Male & 25.27 & 10.46 & 3.31 & $0.00^{* *}$ \\
\hline & female & 18.84 & 7.96 & & \\
\hline \multirow[t]{2}{*}{ Consonant Insertion } & Male & 1.79 & 1.32 & $-0.75-$ & 0.46 \\
\hline & female & 2.03 & 1.24 & & \\
\hline \multirow[t]{2}{*}{ Vowel Insertion } & Male & 4.65 & 3.15 & $-1.24-$ & 0.22 \\
\hline & female & 5.53 & 3.44 & & \\
\hline \multirow[t]{2}{*}{ Consonant Substitution } & Male & 20.15 & 9.68 & 2.43 & $0.02^{* *}$ \\
\hline & female & 15.69 & 7.23 & & \\
\hline \multirow[t]{2}{*}{ Vowel Substitution } & Male & 24.85 & 9.93 & $-0.06-$ & 0.95 \\
\hline & female & 24.98 & 9.52 & & \\
\hline \multirow[t]{2}{*}{ Transposition } & Male & 3.19 & 1.92 & 0.85 & 0.40 \\
\hline & female & 2.78 & 1.87 & & \\
\hline \multirow[t]{2}{*}{ True Word Error } & Male & 4.24 & 1.91 & 2.71 & $0.01^{* *}$ \\
\hline & female & 5.66 & 2.94 & & \\
\hline \multirow[t]{2}{*}{ Complex Spelling Error } & Male & 15.83 & 10.93 & 1.42 & 0.16 \\
\hline & female & 12.63 & 9.90 & & \\
\hline
\end{tabular}

*The average number of misspellings for each student

** The mean difference is significant at 0.05 level 
Table 7

T-test results for differences between males and females in mean spelling errors in question two only

\begin{tabular}{|c|c|c|c|c|c|}
\hline Types of spelling errors & Gender & Mean & SD. & $\mathrm{T}$ & Sig (2-tailed) \\
\hline \multirow[t]{2}{*}{ Consonant Omission } & Male & 1.74 & 1.05 & 1.23 & 0.20 \\
\hline & Female & 2.19 & 1.25 & & \\
\hline \multirow[t]{2}{*}{ Vowel Omission } & Male & 3.00 & 1.88 & 1.47 & 0.15 \\
\hline & Female & 2.37 & 1.57 & & \\
\hline \multirow[t]{2}{*}{ Consonant Insertion } & Male & 1.22 & 0.67 & 1.00 & 0.35 \\
\hline & Female & 1.00 & 0.00 & & \\
\hline \multirow[t]{2}{*}{ Vowel Insertion } & Male & 2.067 & 1.22 & 0.17 & 0.87 \\
\hline & Female & 2.14 & 1.28 & & \\
\hline \multirow[t]{2}{*}{ Consonant Substitution } & Male & 1.86 & 1.03 & 1.17 & 0.25 \\
\hline & Female & 2.33 & 1.35 & & \\
\hline \multirow[t]{2}{*}{ Vowel Substitution } & Male & 3.13 & 2.49 & 0.68 & 0.50 \\
\hline & Female & 3.51 & 2.38 & & \\
\hline \multirow[t]{2}{*}{ Transposition } & Male & 2.00 & 1.05 & 0.76 & 0.45 \\
\hline & Female & 1.75 & 0.79 & & \\
\hline \multirow[t]{2}{*}{ True Word Error } & Male & 2.33 & 2.11 & 1.42 & 0.17 \\
\hline & Female & 1.58 & 1.02 & & \\
\hline \multirow[t]{2}{*}{ Complex Spelling Error } & Male & 1.64 & 0.67 & 1.12 & 0.27 \\
\hline & Female & 2.09 & 1.24 & & \\
\hline
\end{tabular}

Table 7 shows that there were no significant differences between male students and female students with respect to the types of spelling errors found in students' text writing. Although there were mean differences between males and females in vowel omission spelling problem and true word errors, this difference was not significant at 0.05 level. A possible explanation to this finding is the nature of the two types of questions. In the writing question, students needed to bring in more language knowledge in order to compose their writing. The length of what students wrote varied from no writing to two pages. Many students could not write anything even though they were encouraged and assisted by the researchers of the present paper.

Previous spelling studies based on corpus analysis did not compare the types of misspellings made by male and female students in composition writing. Gender difference between the types of spelling errors was not the focus of previous studies. However, the comparison of spelling achievement between male and female learners was the focus of some spelling studies. An Omani study conducted by Al-Yahyai (2009) on grade four male and female students found out that girls were better spellers than their male counterparts in both the pretest and posttest. Allred (1991) studied the achievements of boys and girls from grade one through grade six in the USA and found out that girls were better spellers than boys. The researcher attributed the difference between the two genders to maturity and cultural expectations. According to Allred, girls mature earlier than boys, thus their linguistic performance would most probably be better than boys of the same age. The difference between the different types of spelling errors with respect to gender is an area that needs further investigation.

\section{Conclusion}

Spelling is a complex language skill and the findings from this research study uncovered the different difficulties students face with spelling. Vowel substitution, vowel omission and consonant substitution were the most common types of spelling difficulties Omani students in the present study face. Thus, mastering the spelling of the most frequent English words is something that needs time and a lot of effort. Spelling instruction in Arab EFL in general and in Omani classrooms in particular should be reviewed in order to provide the appropriate spelling instruction that corresponds with students' actual spelling needs. A change to alleviate the spelling problems is necessary. This change needs to combine the efforts of all change agents in education namely curriculum designers, supervisors, trainers and teachers.

\section{Recommendations}

In light of the findings of the present study, the following recommendations are made:

1. Evaluating students' spelling proficiency particularly at the beginning of grade ten in order to measure students' actual achievements in spelling through the nine years of learning English. Subsequently, stakeholders at the curriculum department in the Ministry of Education 
are well informed about students' actual needs and thus can design the most appropriate intervention programs.

2. Teachers need to be well trained to deal with students' spelling difficulties. Therefore, curriculum developers in coordination with training and supervision departments can survey teachers' training needs with respect to teaching and learning spelling. Then, in-service training needs that can correspond with students' actual needs can be designed and implemented.

3. English language syllabus can include more effective spelling learning strategies for students to employ when learning spelling.

4. Further studies on spelling problems might consider investigating the misspellings of different grade levels.

5. Comparisons between the spelling performance of different grade levels, e.g. between grade five and grade ten, are recommended in order to examine whether students make different types of spelling errors as they progress through the years of learning English or not.

6. Testing the effectiveness of a teaching approach or a teaching/learning strategy for spelling is recommended in order to measure their effect on improving students' spelling proficiency.

\section{References}

Al-Harrasi, K. (2012). The most common spelling errors among Omani learners. Arab World English Journal, 3(2), 96 -116.

Al-Hassan, S. (2006). An alternative approach to teaching spelling in grade 5 . In S. Borg (Ed.), Classroom Research in ELT in Oman (pp.81-87). Sultanate of Oman: Ministry of Education.

Al-Jabri, F. (2006). Common English spelling difficulties of Omani learners. In S. Borg (Ed.), Classroom Research in ELT in Oman (pp.88-93). Sultanate of Oman: Ministry of Education.

Al-Jarf, R. (2008). Listening Spelling Strategies in EFL Arab College Students. Retrieved from http://repository.ksu.edu.sa/jspui/bitstr
eam/123456789/7716/1/Listeningspelling $\% 20$ strategies $\% 20 \mathrm{in} \% 20 \mathrm{EFL} \% 20 \mathrm{Ar}$ ab\%20college $\% 20$ students.pdf

Al-Jarf, R. (2010). Spelling error corpora in EFL. Sino-US English Teaching, 7(1), 6-15.

Al-Jayousi, M.T. (2011). Spelling errors of Arab students: Types, causes and teachers' responses. Master Thesis. American University of Sharjah. Retrieved from https://dspace.aus.edu/xmlui/bitstream $\angle$ handle/11073/2716/29.2322011.09\%20Mohannad \%20Al\%20Jayousi.p $\underline{\mathrm{df} \text { ?sequence }=1}$

Allred, R. A. (1990). Gender differences in spelling achievement in grades 1 through 6. Journal of Educational Research, 83(4), 187193.

Al-Mezeini, H. (2009). Does teaching spelling rules make a difference?. In S. Borg (Ed.), Understanding English Language Teaching and Learning in Oman (pp. 124-131). Sultanate of Oman: Ministry of Education.

Al-Yahyai, S. (2009). Spelling Difficulties in Grade 4. In S. Borg (Ed.),Understanding English Language Teaching and Learning in Oman (pp.132-139) Sultanate of Oman: Ministry of Education.

Al-Zuoud, K. \& Kabilan, M. (2013). Investigating Jordanian EFL students' spelling errors at tertiary level. International Journal of Linguistics, 5(3), 164-176.

Anonymous, (2012). Text project. Retrieved from

http://textproject.org/archive/ resources /wordzones-for-4000-simple-wordfamilies/

Apel, K. (2008). Using spelling instruction to improve literacy outcomes. [PowerPoint slides]. Retrieved from http://www.education.canterbury.ac.nz/ seminars/apel_handout09.pdf

Bourassa, D., \& Treiman, R. (2009). Linguistic foundations of spelling development. In D. Wyse, R. Andrews, \& J. Hoffman (Eds.), Routledge international handbook of English, language and literacy teaching (pp. 182-192). London: Routledge.

Brown, H. D. (2000). Principles of language learning and teaching (4th edition). White Plains, NY: Pearson Education. 
Cook, V. (1997). L2 users and English spelling, Journal of Multilingual and Multicultural Development, 18(6), 474-488.

Cook, V. (1999). Teaching spelling. Retrieved from

http://homepage.ntlworld.com/vivian.c/ Writings/Papers/TeachingSpelling.htm

Cramer, R. L. (1998). The spelling connection: Integrating reading, writing and spelling instruction. New York: The Guilford Press.

Department of Education and Children's Services. (2011). Spelling: From beginnings to proficiency. The State of South Australia.

Emery, H. (2005). An investigation into the nature and causes of reading and spelling errors made by Arab ESL learners. (PhD thesis). The University of Wales, Cardiff.

Emery, H. (2008). Eyes and ears. English Teaching Professional, 55, 17-19.

Fashola, O., Drum, P. \& Mayer, R. (1996). A cognitive theory of orthographic transitioning: Predictable errors in how Spanishspeaking children spell English words. American Educational Research Journal, 33(4), 825-843.

Fender, M. (2008). Spelling knowledge and reading development: Insights from Arab ESL learners. Reading in a Foreign Language, 20(1), 19-42.

James, C. (1998). Errors in Language Learning and Use: Exploring Error Analysis. London: Longman.

Jennings, M. (1998). Individualize your spelling instruction! Preventing School Failure: Alternative Education for Children and Youth, 42(1), 44-45. doi: 10.1080/10459889809603168

Kharma, N. \& Hajjaj, A. (1997). Errors in English among Arabic speakers: Analysis and remedy. Beirut: Librairie du Liban.

Kibel, M. \& Miles, T. (1994). Phonological errors in the spelling of taught dyslexic children. Inc.Hulme. \& M. Snoling (Eds.), Reading Development and Dyslexia, London: Whurr Publications.

Kohnen, S., Nickles, L. \& Castles, A. (2009). Assessing spelling skills and strategies: A critique of available resources, Australian Journal of Learning Difficulties, 14(1),
113-150. doi: 10.1080/19404150902783450

Kreiner, D., Schnakenberg, S., Green, A., Costello, M. \& McClin, A. (2002). Effects of spelling errors on the perception of writers. The Journal of General Psychology, 129 (1), 5-17.

Mahmoud, A. (2013). Spelling errors of Arab learners of EFL: A two-way analysis. TESOL Arabia Perspectives, 20(1), 6-12.

McMurray, S. (2006). Learning to spell: Raising standards in spelling and independent writing. Support for learning, 21, 100-107.

Ministry of Education. (1999). English language: Curriculum framework. Sultanate of Oman: Ministry of Education.

Nyamasyo, E. A. (1994). An analysis of the spelling errors in written English of Kenyan pre-university students. Language, Culture and Curriculum [Abstract]. 7(1), 7992. Retrieved from http://www.tandfonline.com/doi/abs/1 0.1080/07908319409525167

Peters, M. L. (1985). Spelling caught or taught: A new Look. London: Routledge \& Kegan Paul plc.

Santoro, L., Coyne, M. \& Simmons, D. (2006). The reading-spelling connection: Developing and evaluating a beginning spelling intervention for children at risk of reading disability. Learning Disabilities Practice, 21(2), 122-133.

Schlagal, B. (2002) Classroom spelling instruction: History, research, and practice. Reading Research and Instruction, 42(1), 4457. doi:

Schonell, F. J. (1985). Essentials in teaching and testing spelling. London: Macmillan.

Stirling, J. (2011). Teaching spelling to English language learners. Raleigh, USA: LULU.

Tavosanis, M. (2007). A causal classification of orthography errors in web texts. Proceedings from AND 2007, 99-106. Retrieved from

http://research.ihost.com/and2007/cd/P roceedings_files/p99.pdf

Treiman, R. \& Kessler, B. (2013). Learning to use an alphabetic writing system. Language Learning and Development, 9, 317330. doi: 10.1080/15475441.2013.812016 
Vaddapalli, M. (2012). Spelling and auditory discrimination difficulties of students in Oman: An analysis. Language in India, 12(1), 261-276.

Warda, R. (2005). Research based tutoring of English spelling: white paper. eSpindle Learning Inc. Retrieved from http://files.eric.ed.gov/fulltext/ED49213 7.pdf

Wasowicz, J. (2007). What do spelling errors tell us about language knowledge? Retrieved from:

http:/ / www.learningbydesign.com/uplo ads/ What_Do_Spelling_Errors_Tell_Us_ Language_Knowledge.pdf 


\section{Appendix A}

\section{The Spelling Words}

\begin{tabular}{|c|c|}
\hline The word & Sentence \\
\hline 1. Angry & Don't drive when you are angry. \\
\hline 2. Beach & I like walking on the beach. \\
\hline 3. camera & Take a photo with your camera. \\
\hline 4. Degree & My brother has a master's degree. \\
\hline 5. Energy & We can make solar energy from the sun. \\
\hline 6. Forest & Many animals live in the forest. \\
\hline 7. got & I've got a nice gift on my birthday. \\
\hline 8. hand & Eat with your right hand. \\
\hline 9. inside & Put the book inside the bag. \\
\hline 10. junk & You shouldn't eat junk food. \\
\hline 11. Кeер & People keep goats in their farms. \\
\hline 12. Leave & You should leave the building if there is fire. \\
\hline 13. market & I bought my new dress from a big market in Matrah. \\
\hline 14. Nine & My sister is nine years old. \\
\hline 15. Orange & An orange is a fruit. \\
\hline 16. paint & Paint the picture with different colors. \\
\hline 17. Queen & A queen lives in a palace. \\
\hline 18. reduce & We should reduce the amount of plastic we use. \\
\hline 19. salary & In some jobs, you get a high salary. \\
\hline 20. team & Our football team won the match. \\
\hline 21. under & There is a bag under the table. \\
\hline 22. very & I like this book very much. \\
\hline 23. Water & Drink at least two litres of water every day. \\
\hline 24. fox & I saw a fox in the zoo. \\
\hline 25. Yet & I haven't finished writing yet. \\
\hline 26. zoo & There are many animals in the zoo. \\
\hline 27. country & Oman is a beautiful country. \\
\hline 28. view & Write your view about the topic. \\
\hline 29. receive & Did you receive my message? \\
\hline 30. elephant & The elephant is a big animal. \\
\hline 31. because & She won the race because she was the fastest. \\
\hline 32. mountain & Al-Jabel Al-Akhdher is a famous mountain in Oman. \\
\hline 33. serious & If you have a serious problem, talk to your parents about it. \\
\hline 34. Creature & A creature is an animal. \\
\hline 35. people & More people live in cities than in villages. \\
\hline 36. daughter & I have one daughter and two sons. \\
\hline 37. Should & You should see a doctor if you are sick. \\
\hline 38. Climb & A monkey can climb a tree. \\
\hline 39. Knife & You need to use a sharp knife to cut that fish. \\
\hline 40. wrong & You don't get marks for wrong answers. \\
\hline 41. Building & Our school is a large building. \\
\hline 42. Chocolate & Children like eating chocolate. \\
\hline 43. chemistry & He studies chemistry at the college. \\
\hline 44. Machine & We need a big machine to dig the well. \\
\hline 45. laugh & I always laugh at the jokes he makes. \\
\hline 46. Language & Arabic is a language of many countries. \\
\hline 47. Would & Would you get me a cup of coffee please? \\
\hline 48. Knew & I knew she could do it. \\
\hline 49. wear & Muslims wear new clothes during Eid. \\
\hline 50. right & Turn right at the roundabout and then go straight. \\
\hline
\end{tabular}




\title{
Appendix A
}

\section{The Spelling Words}

\author{
51. Buy \\ 52. their \\ 53. business \\ 54. education \\ 55. beautiful \\ 56. entertainment \\ 57. walked \\ 58. finished \\ 59. wanted \\ 60. Personality \\ 61. interesting \\ 62. Carefully \\ 63. helpless \\ 64. slowly \\ 65. centimeter \\ 66. unhappy \\ 67. using \\ 68. goats \\ 69. boxes \\ 70. wives \\ Did you buy milk from the supermarket? \\ Their son works in a big company. \\ Some people have their own business. \\ Education in Oman is improving. \\ This is a beautiful flower. \\ Nowadays, there are many activities one can do for entertainment. \\ Yesterday, I walked for 5 kilometers. \\ He finished the report last week. \\ When I was a child I wanted to become a superman. \\ Some people have a lovely personality. \\ It is an interesting movie. \\ You should drive carefully. \\ You shouldn't be helpless when you face a problem. \\ Turtles move slowly. \\ This line is one centimeter long. \\ I was unhappy about my marks. \\ I like using the computer. \\ Farmers usually keep goats and cows in their farms. \\ There are three boxes of mangoes on the shelf. \\ Wives are happy with the new law.
} Sentence 